\title{
Dermoskopide hasta yönetimi
}

\section{Patient management in dermoscopy}

Ișil Kılınç Karaarslan

Ege Üniversitesi Tıp Fakültesi, Dermatoloji Anabilim Dalı, Dermato-Onkoloji Ünitesi, İmir, Türkiye

\section{Özet}

Dermoskopinin primer hedefi olan "melanomun erken tanıı" amacıyla yaptığımız dermoskopik değerlendirmelerde, günlük pratikteki yoğunluk göz önünde bulundurularak, maliyet-etkin bir yaklaşım geliştirmek gerekmektedir. Bu makalede, böyle bir yaklaşım geliştirebilmesi için gerekli "dermoskopide hasta yönetimi" stratejisi konusunda temel özellikler tartışılmaktadır. (Türkderm 2014; 48: 2-6)

Anahtar Kelimeler: Dermoskopi, digital dermoskopi, melanom

\section{Summary}

Considering the work load in daily practice, it's necessary to establish a cost-effective approach in the dermoscopic evaluation for early diagnose of melanoma, which is the primary goal of dermoscopy. In this article, the basic characteristics of "patient management strategy in dermoscopy", which are necessary for such an approach, are discussed. (Turkderm 2014; 48: 2-6)

Key Words: Dermoscopy, digital dermoscopy, melanoma

\section{Giriş}

Günümüzde dermoskopi, başta melanom erken tanısı olmak üzere, infeksiyöz ve inflamatuvar dermatozlar da dahil olacak şekilde dermatolojinin hemen her alanında tanı ve tedavi takibi açısından büyük önem taşımaktadır. Eğer bir dermatolog kendini bu konuda yeterince eğittiyse, el dermoskobunu rutin hasta muayenesinin temel bir parçası haline getirebilir.

Bu makalenin konusu olan "dermoskopide hasta yönetimi", genel dermatolojide kullanımından çok, dermoskopinin temel amacı olan melanomun erken tanınması ile ilgili yapılacakların iyi organizasyon ve uygulamasını ifade etmektedir.
Dermoskopide hasta yönetimi anlayışı geliştirmemiz, birçok nedenle günümüzde zorunlu hale gelmektedir. Hasta sayısının çokluğuna karşın iyi yetişmiş insan gücünün sınırlı olması, önemli bir zaman sorunu oluşturmakta ve yapılan işin maliyet etkin (cost-effective) olup olmadığı sorusunu gündeme getirmektedir. Maliyet etkin ifadesi, sadece parasal açıdan değil, zaman ve enerji açısından da yapılan işe değer olma anlamını taşımalıdır.

Yeterince ilgili, iyi eğitimli, tecrübeli bir hekimin hem "melanom doğru tanı oranını arttıırken yanlış tanı ve gereksiz eksizyon oranını en azda tutabilmesi" hem de "yaptığı işin zaman, enerji, maliyet açısından etkin olabilmesi" ancak "iyi/ doğru hasta yönetimi" varlığında söz konusu olabilir.

Yazışma Adresi/Address for Correspondence: Dr. Işıl Kılınç Karaarslan, Ege Üniversitesi Tıp Fakültesi, Dermatoloji Anabilim Dalı, Dermato-Onkoloji Ünitesi, İzmir, Türkiye E-posta:kilinci35@yahoo.com Geliş Tarihi/Received: 07.12.2013 Kabul Tarihi/Accepted: 10.12.2013 


\section{Genel dermatoloji polikliniğinde dermoskopi ve hasta yönetimi}

Genel dermatoloji polikliniği yapan bir dermatolog, hangi nedenle hastasını görüyor olursa olsun, melanomun ve melanom erken tanısı için kendi öneminin farkında olmalıdır. Ancak bu anlayışı geliştirebilmiş hekimler, risk grubu hastaları diğerlerinden ayırt edebilme yetisine sahip olabilir. Ayrıca hastaların benleriyle ilişkili gözlemlerine değer vermeyi iyi öğrenmiş olmalıdır ve günümüzde çok erken evredeki bir melanomu yakalayabilmek için sahip olduğumuz en önemli ipucunun bu "değişim öyküsü" olabileceğini unutmamalıdır¹.

Bir dermatoloji polikliniğine gelen tüm hastaların melanom açısından tüm vücut muayenesinin yapılabilir olması genel polikliniklerdeki yoğunluk nedeniyle gerçekçi bir beklenti değildir. "Herhangi bir "lokalize" deri şikayeti ile dermatoloji polikliniklerine gelen hastaların tümüne tüm vücut bakısı yapılmalı mı?"sorusuna yanıt bulmaya çalışan bir çalışma, 1 deri kanseri saptamak için 47 kişide, 1 melanom saptamak için ise 400 kişide tüm vücut muayenesi yapmak gerektiğini ortaya koymuştur. Bu çalışmada ileri yaş, deri tipi I-II olması ve daha önce deri kanseri öyküsü olması durumlarında, tüm vücut muayenesi yapılmasının deri kanserlerinin erken yakalanabilmesi için önem taşıdığı bildirilmiştir2 (Resim 1).

Genel dermatoloji polikliniğinde melanomun erken yakalanması açısından kimlere tüm vücut muayenesi yapılması gerektiği, hastanın risk faktörlerini taşıyor olup olmamasına göre belirlenebilir (Tablo 1). Melanom ve displastik nevüs sendromu tanısı alanlar ve bunlarının birinci derece yakınları mutlaka düzenli aralıklarla tüm vücut muayenesine davet edilmelidir (Resim 2, 3, 4, 5). Tüm vücut muayenesi mutlaka palmoplanter bölge, tırnaklar, saçlı deri, kulak arkası ve mukozaların muayenesini içermelidir1.

Genel dermatolojik değerlendirme sırasında risk grubunda olduğu tespit edilen hastalar içinde kimlerin sadece klinik olarak tüm vücut muayenesi ile izlenebileceği, kimlerin dermoskopik olarak da değerlendirilmesi gerektiği, kimlerin digital dermoskopik izleme alınması gerektiği de kararlaştıııması gereken önemli konulardır.

Riskli fenotipte olan, solar hasarı belirgin olan veya herhangi bir nedenle immunsuprese olan bir hastanın genel dermatolojik bakısında nevüsü olmadığı veya birkaç banal nevüsü olduğu saptanırsa, hastanın güneşten korunma ve kendi kendini muayene konusunda bilgilendirilmesi ve yıllık klinik muayene ile izlemi önerilebilir33.

Riskli fenotip, solar hasar, veya immunsupresyon gibi risk faktörleri olan ve çok sayıda banal nevüsü olan bir hasta için ise güneşten korunma ve kendi kendini muayene konusunda bilgilendirilme yanı sıra yıllık klinik muayene ile eş zamanlı dermoskopik inceleme önerilebilir ${ }^{3}$.

Genel dermatolojik muayene sırasında diğer risk faktörlerini taşımadığı ancak sadece bir atipik nevüsü olduğu saptanan hastada, o lezyonun eksizyonu önerilmelidir. Tek bir lezyonun uzun dönem takibi önerilmez 4 . Güneşten korunma ve kendi kendini muayene konusunda bilgilendirme ve yine yıllık klinik ve dermoskopik muayene önerilmelidir.

Dermoskopik muayene sırasında dikkat edilmesi gerekenler:

Dermoskopik incelemenin sadece klinik olarak seçilmiş lezyonlar için değil tüm lezyonlar için uygulanması gerekliliği unutulmamalıdır. Klinik özelliği ve çapı ne olursa olsun tüm lezyonlar dermoskopik olarak değerlendirilmeli ve melanom düşündürebilecek özelliklerden (Tablo 2) herhangi birinin varlığı açısından dikkat edilmelidir. Tüm lezyonlar için dermoskopik inceleme yapılarak hastada genel nevüs paterninden

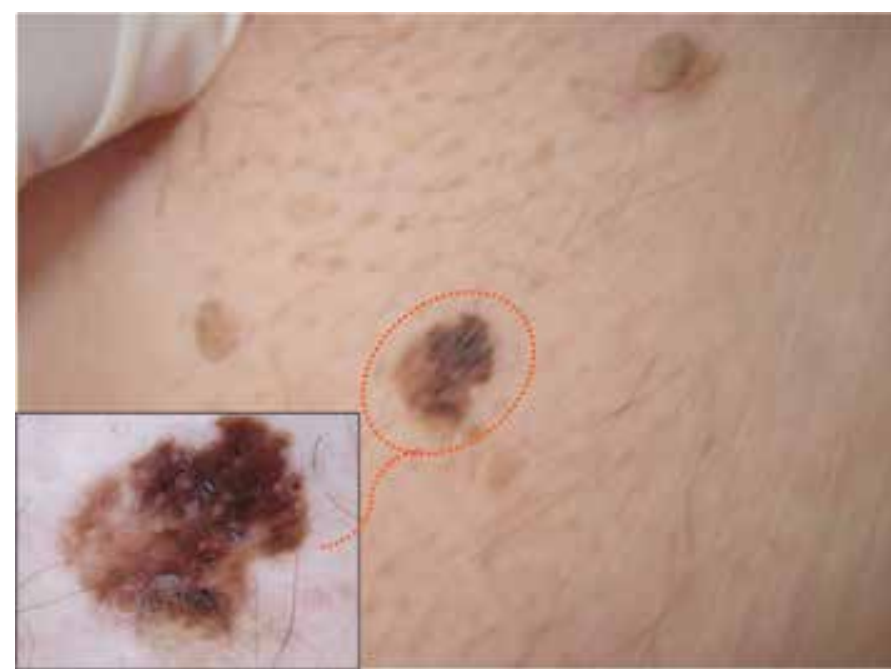

Resim 1. Seksen yaşındaki kadın hastada tırnak yatağında saptanmış olan SCC sonrası yapılan tüm vucut muayenesinde saptanan lentiginöz melanoma in situ

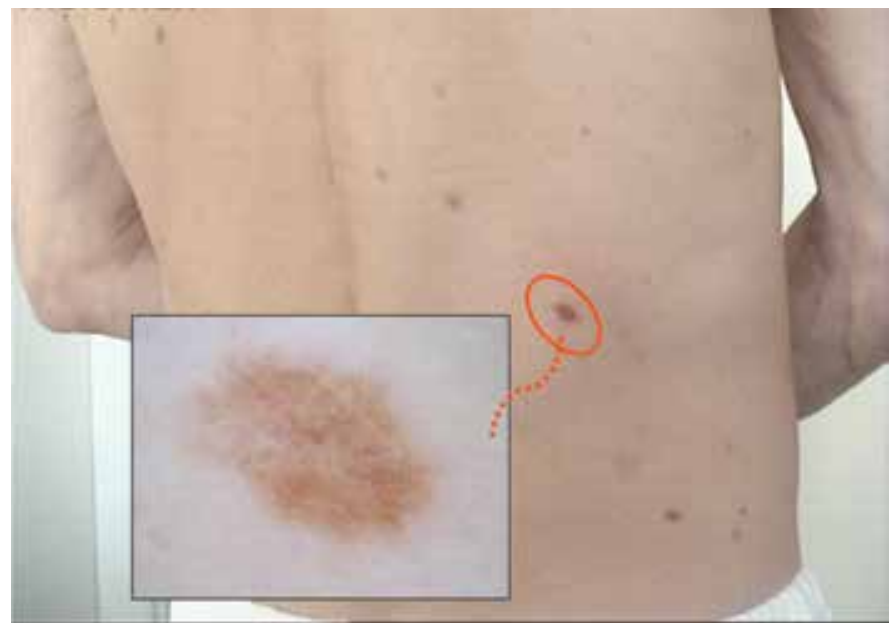

Resim 2. Yetmiş yaşında erkek hasta. Oğlu displastik nevüs sendromu nedeni ile izlenmekte iken aile anamnezinde babada benzer lezyonların olduğu belirtilmesi üzerine muayeneye davet edilen ve babada saptanan melanoma in situ lezyonu

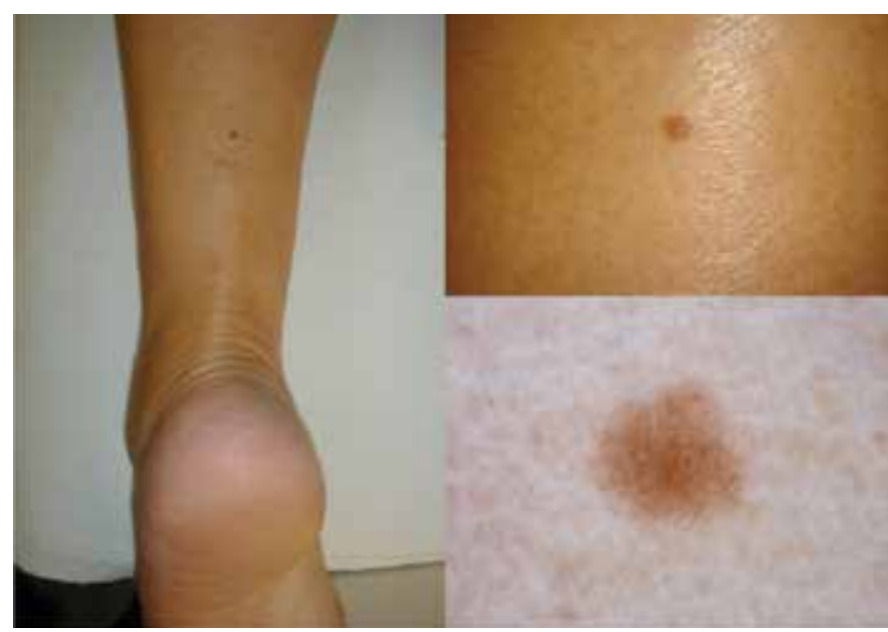

Resim 3. Daha önce melanom öyküsü olan 60 yaşında kadın hastanın izlemi sırasında saptanan melanoma in situ 
farklı olan lezyonun fark edilmesi ile, klinik olarak "şüpheli görünümde olmayan ama aslında çok erken bir melanom olan" bir lezyonun yakalanabilmesi sağlanabilir. Hastada genel nevüs paterninden farklı olan bir lezyona, melanom düşündüren dermoskopik özellikler taşımasa dahi şüpheyle yaklaşıımalıdır. Öte yandan hastada benzer özellikleri paylaşan baskın nevüs paterninin saptanmasıyla "benzer paternde olan lezyonların riskli olma ihtimalinin düşük" olması nedeni ile gereksiz eksizyon oranı azaltılabilir5.

Hekimlerin hastadaki her bir lezyona dermoskopik inceleme yapmama nedenleri zaman kısıtılığı, eğitim yetersizliği, lojistik sınılılıklar, ilgi eksikliği, ödeme olmaması ve dermoskopinin yararına inanmama olarak bildirilmiştir6. Bunların giderilmesi için emek sarf edilmelidir. Tüm lezyonların dermoskopik olarak değerlendirilmesinin çok uzun zaman alabileceği düşünülebilir ve dermoskopiyi yeni öğrenmekte olanlar için bu geçerli olabilir. Ancak dermoskopi konusunda kendini iyi eğitmiş ve yeterli pratik deneyimi olan bir dermatolog için, bu süre,

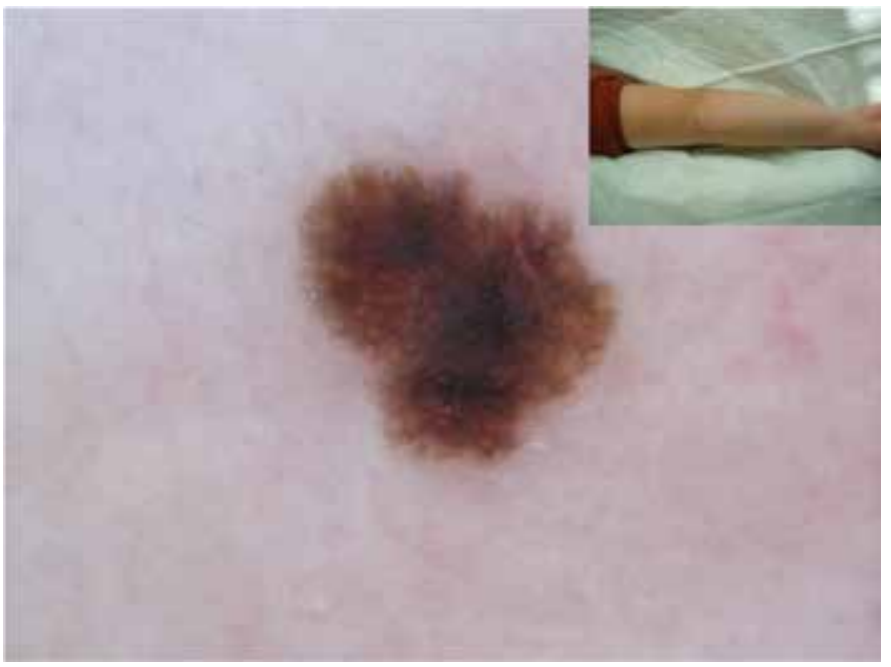

Resim 4. Dedesinde melanom öyküsü olması nedeni ile tüm vucut muayenesi yapılan 16 yaşında kız hastada saptanan mikro-melanoma in situ $(3 \times 2.5 \mathrm{~mm})$

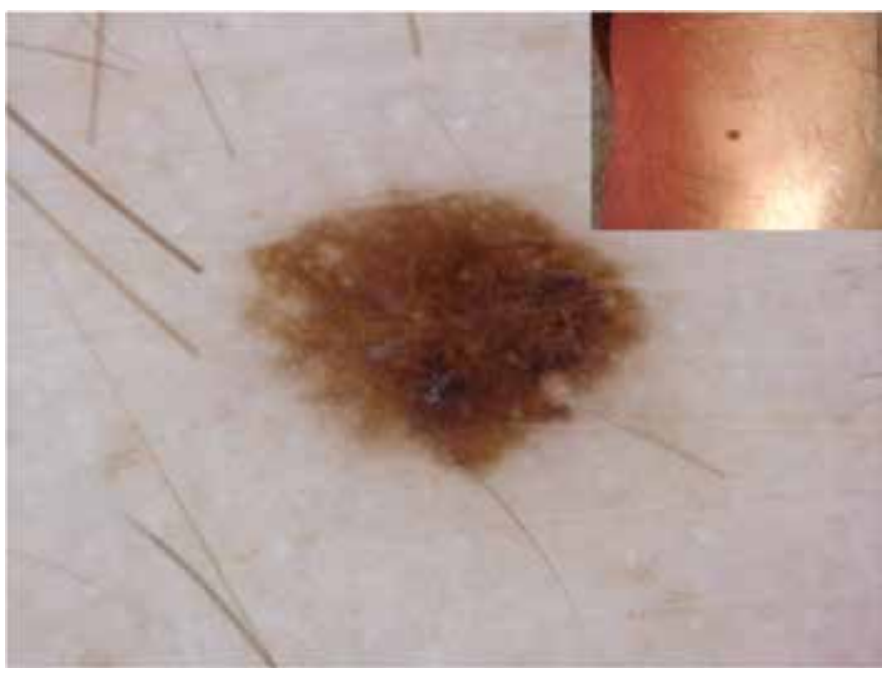

Resim 5. Çok sayıda nevüsü nedeni ile izleme alınmış olan 65 yaşındaki erkek hastada sol dizinde saptanmış olan mikro-melanoma in situ (3x3 mm). elde edilebilecek yararlar göz önünde bulundurulduğunda son derece kabul edilebilir bir süredir. Dermoskopi eğitimi teorik olarak algoritmalar üzerinden olduğu için başlangıç aşamasında olan bir hekimin lezyonları algoritmalar üzerinden değerlendirme çabası nedeni ile süre uzun olabilmektedir. Ancak yeterli teorik bilgi üzerine yeterince pratik yapıldığında, sık tekrar sonucu gözümüz ve beynimiz patern tanıma ve lezyonun bir bütün olarak algılanması konusunda eğitilir. İnsanın görsel algısı, kompleks bir görüntüyü çok kısa süre görse bile çok hızlı bir şekilde tanımlayabilme yeteneğindedir6. Böylelikle dermoskopik değerlendirme çok daha seri bir şekilde yapılabilir. Deneyimli bir dermatolog için, dermoskopi ile yapılan tüm vücut muayenesinin, dermoskop kullanılmadan yapılan muayeneye göre sadece 72 sn daha fazla zaman aldığı bildirilmiştir7. Ancak dermoskopi konusunda çok deneyimli olan dermatologlar bile yaptıkları dermoskopik muayene sırasında "zor lezyonlar"ın var olduğu gerçeğini unutmayıp, riskli bir lezyona işaret edebilecek en ufak bir ip ucunu bile fark edebilecek şekilde dikkat ve konsantrasyon sağlamak zorundadırlar.

Dermoskopik değerlendirme yapan dermatologlar, mutlaka dermoskopik-dermatopatolojik korelasyon için dermatopatolog ile sürekli iletişim halinde olmalı ve lezyonun dermoskopik olarak en atipik olduğu alandan kesit yapılabilinmesini sağlamalıdır. Unutulmamalıdır ki dermoskopistler dermoskopla lezyonun tümünü değerlendirebilirken, patologlar ancak makroskopik olarak değerlendirdikleri lezyonun belli alanlardan kesit alarak değerlendirme yaparlar. İleri tümörler için bu yöntemde genellikle tanı açısından sorun yaşanmaz. Ancak dermoskopinin temel hedefi, melanomu oldukça erken bir evrede yakalamak olduğu için dermoskopide şüpheli görülen alandan kesit alınmasını sağlamak son derece önemlidir.

\section{Tablo 1. Risk faktörleri}

Yüksek risk
Kendisinde veya ailesinde melanom öyküsü olması
Kendisinde veya ailesinde displastik nevüs sendromu olması
Diğer
Deri tipi I-II, sarı veya kızıl saç, mavi göz
Atipik nevüs varlığı
Çok sayıda nevüs varlığı
Güneşe aralıklı maruziyet ve özellikle çocuklukta güneş yanığı öyküsü
Kronik solar hasar
Immunsupresyon

\section{Tablo 2. Melanom spesiffk özellikler ve kriterler}

Asimetri
Çoklu patern varlığı
Çoklu renk varlığı
Atipik ağ yapısı
Düzensiz nokta/globüller
Düzensiz ışınsal yapılar
Düzensiz pigmentasyon
Regresyon yapıları
Mavi-beyazımsı yapı
Düzensiz vasküler patern

Asimetri

Çoklu patern varlığ

Çoklu renk varlığ

Atipik ağ yapıs

Düzensiz nokta/globüller

Düzensiz ışınsal yapılar

Duzensiz pigmentasyon

avi-beyazımsı yap 


\section{Dermoskopi/dijital dermoskopi konusunda özelleşmiş bir ünitede hasta yönetimi}

Çok sayıda atipik nevüsü olan hastada, birçok lezyon klinik olarak $A B C D$ pozitif özellik taşıyabilir. El dermoskobu ile değerlendirildiğinde bile, birçok lezyonda dermoskopik olarak irregüler özellikler görülebilir ve bu tip hastalarda gereksiz eksizyon oranı yüksek olabilir. Bu zor hastalarda ancak digital dermoskopik izlem gereksiz eksizyon oranını azaltabilir.

Bir nevüsün digital dermoskopik izleminde değişim varlığı, melanomu çok erken- belki de melanomun klinik ve dermoskopik olarak tanınmasının güç olduğu aşamada tanısını mümkün kılabilirken, izlemde stabil olması gereksiz eksizyon oranını azaltmaktadır8.

Digital dermoskopik izlem, kısa dönem veya uzun dönem izlem şeklinde yapılabilir. Yüksek riskli gruptaki hastalar için uzun dönem digital dermoskopik izlem önerilmelidir. "Yüksek risk grubu" dışındaki riskli hastalar ve lezyonunda değişim öyküsü olan veya atipisi belirgin lezyonları olan hastalar için ise kısa dönem izlem önerilebilir8. Özellikle yüksek risk grubu hastalarda yapılacak izlemler, dermoskopi/dijital dermoskopi konusunda özelleşmiş bir ünite gerektirir. İyi bir özelleşmiş ünite için, yeterli cihaz, yeterli fiziksel mekan, iyi bir arşiv sistemi ve iyi eğitimli bir ekip gereklidir.

Digital dermoskopik izleme karar verilen hastalar arasında kimler ne sıklıkta ve ne kadar süre izlenmelidir sorusunun cevabı özelleşmiş bir ünitede hasta yönetiminin temelini oluşturmaktadır. Bu sorulara cevap verecek şekilde bir hasta yönetimi planı oluşturulmaması o ünitede zaman içinde gerçekten uzun dönem izlem endikasyonu olmayan birçok hastanın uzamış takibi nedeniyle yığılmalara ve randevu verilebilmesinde güçlüklere neden olabilir.

Kısa dönem izlemde genellikle 3 ay ara ile ve az sayıda lezyon izlenirken, uzun dönem izlemde ise 6-12 ay ara ile izlem yapılır ve çok sayıda nevüs izleme alınır. Yüksek riskli hastalar için izlem ömür boyu devam etmelidir8.

Digital dermoskopik izlem sırasında başlangıç ve kontrol görüntüleri arasında yapılan kıyaslamalarda fark edilen değişikliklerin doğru yorumlanabilmesi doğru tanı oranının arttırılması ve gereksiz eksizyon oranının azaltılması açısından son derece önemlidir.

Değişimin belli bir lezyonda mı yoksa hastadaki lezyonların çoğunda mı olduğuna dikkat edilmelidir. Birçok lezyonda değişim varsa ultraviyoleye maruziyet, fototerapi, gebelik, ilaç kullanımı açısından sorgulanmalı ve özellikle yetişkin hastalarda değişim stabilleşene kadar izlenmelidir. Belli bir lezyonda değişim varlığında ise hastanın çocuk veya yetişkin olması, lezyonun son muayenesindeki dermoskopik özellikleri (özellikle melanom düşündüren dermoskopik özelliklerin olup olmaması) ve değişimin türü önemlidir.

Çocuk ve adölesan yaş grubunda bir hastadaki tipik bir lezyonda gözlenen simetrik büyüme eksizyon gerektirmez. Bir yetişkinde ise tipik özelliklerde bir lezyonda bile büyüme önemlidir ve bu büyüme simetrik bile olsa dikkatli izlem gerekir ${ }^{9}$. Çocuk veya yetişkinde lezyon atipik ise büyüme simetrik bile olsa eksizyon önerilmelidir ${ }^{10}$.

Periferal kahverengi globül sırası (Resim 6) büyüyen nevüslerin karakteristik bulgusudur. Tipik olarak pubertede gelişmekte olan nevüslerde görülür. Digital dermoskopik izlemde simetrik genişleme, periferal globüllerin kaybolması ve nevüs çapında stabilleşme görülür11. Yetişkinde görüldüğünde ise o lezyon çok dikkatli izlenmelidir.

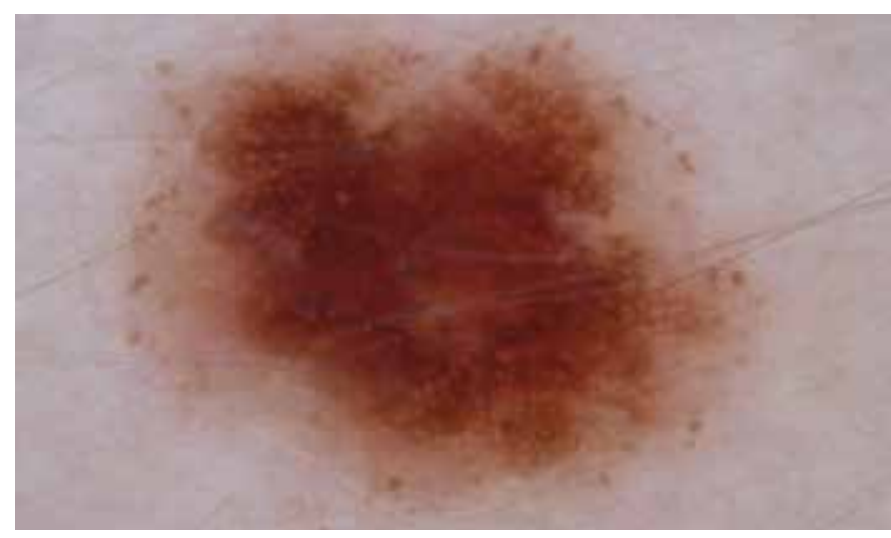

Resim 6. Periferal kahverengi globül sırası

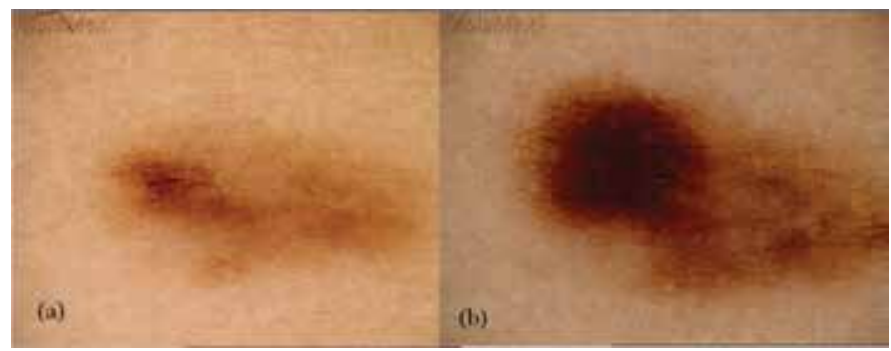

Resim 7. İzlemde olan bir hastada gebelik döneminde saptanmış olan melanoma in situ

Ultraviyoleye maruziyet, digital dermoskopik izlem sırasında nevüslerde görülen değişimin belki de en sık nedenidir. Ultraviyoleye maruziyet sonucunda renkte koyulaşma, çap artışı, pigment ağının kaybolması, eritem, irregüler nokta yapıları, globüller veya leke (blotche) oluşumu görülebilir10,11. UVB/PUVA fototerapi alan hastalarda nevüslerde çap artışı, pigmentasyonun koyulaşması, nokta ve globül yapılarında artış bildirilmiştir12. Bu değişimler geri dönüşümlüdür.

Gebelik sırasında da nevüslerde değişim sık görülmektedir. Çap artışı, renkte koyulaşma veya açıma, ağ yapısında belirginleşme, yeni nokta yapıları veya globüllerin oluşumu, vaskülarizasyon artışı görülebilmektedir. Bunlar genellikle geri dönüşümlüdür. Öte yandan gebelikte nevüslerde tanısal güçlüklere yol açan değişiklikler görülebilir. Bu değişiklikler gebelik süresi ile paralel artış göstermektedir. Genellikle doğumdan 3-6 ay sonra geri döner. Gebelikte 3 ay aralıklı muayenede görülen herhangi bir değişiklik şüpheyle karşılanmalı ise de kısa süreli digital dermoskopik izlem sırasında fizyolojik değişiklikler de göz önünde bulundurulmalıdır ${ }^{11}$. Gebeliği sırasında veya hemen doğum sonrası melanom tanısı almış hastaların varlığı (Resim 7) göz önünde bulundurularak özellikle yüksek risk grubu hastaların gebelikleri boyunca ve doğum sonrası ayları da kapsayacak şekilde kontrol aralıklarının sıklaştırılması önerilebilir.

Digital dermoskopik izlem sırasında şüpheli olarak değerlendirilmesi gereken değişimler özellikle fokal genişleme sonucu şekil değişimi, regresyon, yeni renk oluşumu ve yapısal değişimdir. Yeni renk oluşumu zaten var olan bir renkte koyulaşma veya açılma ile karıştırılmamalıdır. Belirgin ve irregüler ağ yapısı oluşması, pigment ağının kaybolması ve yerine yapısız alan oluşumu, negatif ağ yapısı, mavi-beyaz yapı oluşması çok dikkatli olmayı gerektiren yapısal değişimlerdir.

Digital dermoskopik izlem sırasında dikkat edilmesi gerekenler: Uzun dönem digital dermoskopik izlemin başarısı "saptanan melanom 
Tablo 3. Farklı hekim gruplarında saptanan melanom/ toplam eksizyon oranları

\begin{tabular}{|ll|}
\hline Pratisyenler & $1 / 20-40$ \\
\hline Dermoskopi uygulamayan drmatologlar & $1 / 15$ \\
\hline Dermoskopi uygulayan dermatologlar & $1 / 4,3$ \\
\hline Digital dermoskopi uygulayan dermatologlar & $1 / 3,4$ \\
\hline
\end{tabular}

sayısı/toplam eksizyon sayısı" oranı ile değerlendirilir. Bu oran, 1 melanom yakalamak için toplam kaç eksizyon yapıldığını ifade eder (Tablo 3)3,13. Digital izlem başarısı ne oranda "yüksek riskli" hastaların izleme alındığı, ne kadar uzun süreli izlem yapıldığı ve ne kadar çok sayıda lezyonun izleme alınıyor olduğu ile ilişkilidir8.

Digital dermoskopik izleme alınan yüksek riskli hastalarda, kontrol randevusunda sadece kayıtlı lezyonların izlem görüntüsü alınmakla yetinilmemeli, el dermoskobu ile genel vücut taraması da 6 ay-yılda bir olmak üzere tekrar edilmelidir 3 .

Nodüler lezyonların ve erişkinde Spitzoid leyonların hiçbir zaman digital dermoskopik izleme alınmaması gerektiği unutulmamalıdır.

Digital dermoskopik izlemde zorluklar:

Digital dermoskopik izlem uygulanmasında zorluklar, zaman alıc olması, eğitim ve deneyim gerektirmesi ve spesifik cihaz gerektiren bir teknik olmasıdır ${ }^{14}$. Bu zorluklar nedeni ile özelleșmiş ünitelerin sayısı kısıtlıdır ve bu bunun sonucunda hastalar açısından ulaşım güçlüğü oluşmakta ve var olan üniteler açısından ise aşırı hasta yoğunluğu oluşmaktadır. Bu tip ünitelerin geliştirilmesi ve sayılarının arttırıması için daha çok emek sarf edilmelidir.

Digital dermoskopik izlem açısından diğer önemli bir konu da hastaların bu izlem programına uyum sağlayabilmesi ile ilişkilidir. Uzun dönem izlem planlanan hastalarda izleme başlarken, hasta, yarar ve olası zorluklar konusunda bilgilendirilmeli ve sadece programa uyumlu olabilecek hastalar izleme alınmalıdır. Uzun dönem izleme hasta uyumunun \%46 oranında olduğu bildirilmiştir. Hasta uyumsuzluk nedenlerinin başında, o üniteye ulaşım zorluğu ve muayene günü kliniklerde bekleme süresinin uzun olması gelmektedir5.

\section{Sonuc}

Ülkemizde ne yazık ki hala geç tanı almış melanom hasta oranının yüksek olması, hem hekimler arasında melanom farkındalığını arttırmak hem de dermoskopinin ülkemizde çok daha yaygın olarak öğrenilmesi ve etkin bir şekilde kullanılabilmesi için gayret sarf etmemiz gerektiğini göstermektedir. Bu konuda var olan olanakların ideal şekilde kullanılabilmesi için "iyi/doğru hasta yönetimi" mutlaka göz önünde bulundurulmalıdır.

\section{Kaynaklar}

1. Bowling J, Argenziano G, Azenha A, et al: Dermoscopy key points: recommendations from the international dermoscopy society. Dermatology 2007;214:3-5

2. Argenziano G, Zalaudek I, Hofmann-Wellenhof $R$, et al: Total body skin examination for skin cancer screening in patients with focused symptoms. J Am Acad Dermatol 2012:66:212-9.

3. Haenssle HA, Korpas B, Hansen-Hagge C, et al: Selection of patients for long-term surveillance with digital dermoscopy by assessment of melanoma risk factors. Arch Dermatol 2010;146:257-64.

4. Schiffner R, Schiffner-Rohe J, Landthaler M, Stolz W: Long-term dermoscopic follow-up of melanocytic naevi: clinical outcome and patient compliance. $\mathrm{Br}$ J Dermatol 2003;149:79-86.

5. Argenziano G, Catricalà $C$, Ardigo M, et al: Dermoscopy of patients with multiple nevi: Improved management recommendations using a comparative diagnostic approach. Arch Dermatol 2011;147:46-9.

6. Jaimes N, Dusza SW, Quigley EA, et al: Influence of time on dermoscopic diagnosis and management. Australas J Dermatol 2013;54:96-104.

7. Zalaudek I, Kittler H, Marghoob AA, et al: Time required for a complete skin examination with and without dermoscopy: a prospective, randomized multicenter study. Arch Dermatol 2008;144:509-13.

8. Salerni G, Terán T, Puig S, et al: Meta-analysis of digital dermoscopy followup of melanocytic skin lesions: a study on behalf of the International Dermoscopy Society. J Eur Acad Dermatol Venereol 2013:27:805-14.

9. Kittler $H$, Seltenheim M, Dawid M, et al: Frequency and characteristics of enlarging common melanocytic nevi. Arch Dermatol 2000;136:316-20.

10. Kittler H, Pehamberger $H$, Wolff K, Binder M: Follow-up of melanocytic skin lesions with digital epiluminescence microscopy: patterns of modifications observed in early melanoma, atypical nevi, and common nevi. J Am Acad Dermatol 2000:43:467-76

11. Zalaudek I, Docimo G, Argenziano G: Using dermoscopic criteria and patient-related factors for the management of pigmented melanocytic nevi. Arch Dermatol 2009;145:816-26.

12. Kilinc Karaarslan I, Teban L, Dawid M, Tanew A, Kittler H: Changes in the dermoscopic appearance of melanocytic naevi after photochemotherapy or narrow-band ultraviolet B phototherapy. J Eur Acad Dermatol Venereol 2007;21:526-31

13. Tromme I, Sacré L, Hammouch F, et al: Availability of digital dermoscopy in daily practice dramatically reduces the number of excised melanocytic lesions: results from an observational study. Br J Dermatol 2012;167:778-86.

14. Salerni G, Carrera C, Lovatto L, et al: Benefits of total body photography and digital dermatoscopy ("two-step method of digital follow-up") in the early diagnosis of melanoma in patients at high risk for melanoma. J Am Acad Dermatol 2012:67:17-27. 